Revista de
Economild
Contemporâned

\title{
O IMPOSTO SOBRE GRANDES FORTUNAS NO BRASIL: PROPOSTAS E SIMULAÇÕES
}

\begin{abstract}
Natassia Nascimento ${ }^{a}$

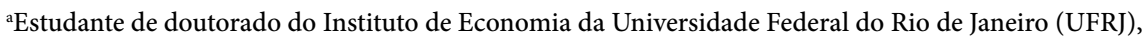
Rio de Janeiro, RJ, Brasil. ORCID: https://orcid.org/0000-0002-2146-7879.
\end{abstract}

\author{
Recebido em 06 maio 2019 \\ Aceito em 21 maio 2021 \\ Received on 06 May 2019 \\ Accepted on 21 May 2021
}

RESUMO: O Brasil é o único país que figura entre os 20 mais ricos e os 20 mais desiguais. Tem um dos maiores programas de redistribuição de renda do mundo, o Bolsa Família, mas também uma das mais injustas cargas tributárias. A tributação e a desigualdade econômica são dois temas principais e de suma importância nos países ainda em desenvolvimento. Em um ambiente de estagnação econômica, o governo priorizou o corte nos gastos como medida de equilíbrio fiscal. Diante desse contexto, este trabalho tem por objetivo propor a implementação do Imposto sobre Grandes Fortunas e analisar sua viabilidade e arrecadação através de simulações com a base de dados do Imposto de Renda. Demonstra-se que o Imposto sobre Grandes Fortunas é viável, teria sólida arrecadação e poderia ser utilizado como instrumento de justiça fiscal. Também contribuiria para o equilíbrio nas contas públicas, sem a necessidade de se realizar cortes em setores fundamentais para o crescimento e bem-estar do Brasil.

PALAVRAS-CHAVE: carga tributária bruta; desigualdade; tributação; imposto sobre grandes fortunas; Brasil.

CLASSIFICAÇÃO JEL: H20; D631; O54. 


\title{
WEALTH TAX IN BRAZIL: PROPOSALS AND SIMULATIONS
}

\begin{abstract}
Brazil is the only country among the 20 richest and the 20 most unequal. It has one of the largest income redistribution programs in the world, Bolsa Família, but also one of the most unjust tax burdens. Taxation and economic inequality are two of the most important issues in developing countries. In a situation of economic stagnation, the government prioritized cutting expenses as a measure of fiscal balance. This paper aims to analyze the implementation of a Wealth Tax, its feasibility and tax collection by simulation with data from tax declarations. It is shown that the Wealth Tax is feasible, has a solid revenue and could be used as an instrument of fiscal justice. It could also help with fiscal equilibrium instead of other austerity measures such as cuts in expenses of essential sectors to the economic growth and well-being of Brazil.
\end{abstract}

KEYWORDS: tax burden; inequality; taxation; wealth tax; Brazil. 


\section{INTRODUÇÃO}

Que o Brasil é um dos países mais desiguais do mundo, todos sabem. Que o Brasil tem um dos principais programas de combate à pobreza do mundo, ${ }^{1}$ muitos também sabem. Que a carga tributária brasileira é elevada e mal formulada, alguns sabem. O que poucos sabem é que quem está no topo da distribuição de renda deste país tem menos de 35\% de sua renda tributada. E o que quase ninguém sabe é como a tributação da riqueza, em suas variadas formas, pode contribuir para redução da desigualdade.

O Brasil é o único país que figura entre os 20 mais ricos no mundo e os 20 mais desiguais. Isso se deve ao fato de o país ter muitas pessoas em situação de extrema pobreza, e também alguns poucos muito ricos, o que concentra muito a renda. Entre 2000 e 2015 houve uma queda no Índice de Gini do Brasil de 0,596 para 0,519, devido principalmente às transferências de renda e à valorização do salário mínimo ocorrida no período. A melhora do mercado de trabalho - que reduziu o desemprego e garantiu os direitos provenientes do emprego formal - foi fundamental para essa queda. No entanto, a partir de 2015, o Índice de Gini voltou a subir, e hoje se encontra em 0,539 (IPEA, 2020).

O aumento da desigualdade nos últimos anos é reflexo imediato da piora da situação econômica. Desde 2014, o Brasil enfrenta uma estagnação econômica e aumento do desemprego, que geram efeitos negativos para o bem-estar. Como forma de combater o desequilíbrio das contas púbicas, o governo optou por políticas de medidas austeras, como corte ou limitação dos gastos (PEC dos gastos), reformas da aposentadoria e desregulamentação do mercado de trabalho.

As políticas fiscais restritivas adotadas vêm prejudicando o financiamento das políticas sociais sem trazer, no entanto, a prosperidade econômica e os resultados esperados no equilíbrio das contas públicas. Por ser majoritariamente composta por tributos indiretos, a arrecadação brasileira depende diretamente da atividade econômica, ou seja, a queda na atividade econômica leva a um declínio na arrecadação, pois quando se compra um produto, uma parte se converte em arrecadação do Estado por meio de impostos. Assim, pode-se afirmar que essa é uma variável "pró-cíclica”, ou seja, quando o ciclo econômico está em fase ascendente, quando a renda está crescendo e as pessoas estão gastando mais, a arrecadação do Estado também cresce. Analogamente, quando o crescimento econômico desacelera, as receitas do governo diminuem.

A arrecadação tributária sofreu uma pequena queda que acabou afetando as contas do governo justamente em um momento em que mais gastos deveriam ser efetuados para impulsionar a retomada do crescimento. A solução proposta pelo governo para o

\footnotetext{
1 O Programa Bolsa Família atende mais de 13 milhões de famílias no Brasil.
} 
ajuste fiscal foi por meio do corte de gastos, em especial das áreas mais carentes como a educação, a saúde e o assistencialismo.

Em um momento de recessão econômica, mais políticas sociais são demandadas como forma de mitigar os riscos de instabilidade financeira pelos quais passam as famílias. Isto é, o estado de bem-estar deveria ser ampliado e não reduzido com política de corte de gastos. Isso implica em um papel mais atuante do Estado que precisa ser financiado pela tributação, ou seja, a necessidade de se ter um sistema tributário equilibrado para a provisão de bens públicos e alívio da pobreza. O Brasil já foi considerado pela Organização das Nações Unidas (ONU) como um “campeão na luta contra a fome e a desnutrição", porém, no relatório de 2015, considerou errôneas as medidas de austeridade estabelecidas pelo governo para os problemas econômicos e defendeu políticas alternativas, tais como ampliar os impostos sobre os mais ricos (ONU, 2015).

Nesse sentido, este artigo visa caracterizar o Imposto sobre Grandes Fortunas (IGF) e como este pode ser utilizado como instrumento de justiça social e redistribuição de recursos. $\mathrm{O}$ estudo propõe que a implementação do IGF ajudaria a sanar as contas públicas, não sendo necessários cortes em áreas de extrema importância para a sobrevivência e o bem-estar da população. Pretende-se responder à seguinte pergunta: O Imposto sobre Grandes Fortunas é viável e tem arrecadação sólida? A hipótese inicial é de que sim, a implementação desse tributo tem base de cálculo suficiente e sua arrecadação seria considerável, o que permitiria não só limitar o acúmulo da riqueza como também redistribuir seus recursos aos mais pobres.

A fim de responder tal pergunta, este artigo está estruturado da seguinte forma: a primeira seção mostra a desigualdade através de dados da Receita Federal que denotam a concentração de renda e riqueza; a segunda seção mostra o atual panorama da tributação brasileira e descreve o IGF; a terceira apresenta a metodologia de cálculo e simula a arrecadação do IGF; e a quarta apresenta os resultados. A conclusão fecha os argumentos e um apêndice mostra o resumo das propostas do IGF analisadas.

\section{CONCENTRAÇÃO DE RENDA E RIQUEZA NO BRASIL}

Embora a desigualdade tenha reduzido, o estudo de Medeiros, Souza e Castro (2015), que conta com dados da tributação, mostrou que as faixas de renda mais ricas concentram cada vez mais renda. O percentual de renda auferido pelos $5 \%$ mais ricos do Brasil subiu de $40 \%$ da renda total para quase 50\% entre 2006 e 2012. A acumulação de renda entre o $1 \%$ e o $0,1 \%$ mais ricos também cresceu, concentrando respectivamente $25 \%$ e $10 \%$ da renda total nacional. 
O estudo de Piketty e Marc Morgan (WID, 2017) estima que, em 2013, os 10\% mais ricos do Brasil tinham renda mensal superior a $\mathrm{R} \$ 4.191,88$; os $5 \%$ mais ricos, renda mensal superior a R\$7.536,61; o 1\% mais ricos, renda mensal superior a R\$23.128,71. Estima, ainda, que o $0,1 \%$ mais ricos tinha renda mensal superior a $\mathrm{R} \$ 89.971,47$; o $0,05 \%$ mais ricos, renda mensal superior a $\mathrm{R} \$ 428.849,47$; e a "cereja do bolo" da distribuição brasileira, o 0,01\% mais ricos, renda superior a $\mathrm{R} \$ 690.829,25$ mensais!

Outros estudos, tais como o World Income Database apresenta dados semelhantes e mostra que o $1 \%$ mais rico concentra quase $28 \%$ da renda total nacional para o ano de 2015; enquanto dados das Declarações do imposto de renda (DIRPF) apontam para uma concentração de $10 \%$ em 2018.

Apesar da maior precisão dos dados da Receita Federal em comparação às pesquisas domiciliares, esses ainda podem estar subestimados, pois não levam em conta dados de Pessoas Jurídicas (PJ) no IR. Muitos trabalhadores autônomos (médicos, dentistas, advogados) declaram imposto de renda como PJ a fim de pagar menos tributos, já que lucros e dividendos não são tributados no Brasil. E, a maior parte da renda de quem está no topo da distribuição vem justamente de rendas "não tributáveis ou isentas".

Usando os dados disponíveis nas DIRPF de 2018, elaborou-se a Tabela 1, na qual os rendimentos estão organizados em relação à quantidade de salários mínimos mensais que, em 2018, era de R\$954,00.

Nesta tabela, a maior parte das declarações, $27,3 \%$ do total, está na faixa de 3 a 5 salários mínimos ( $\mathrm{R} \$ 2.862,00$ a $\mathrm{R} \$ 4.770,00)$. As três primeiras faixas, que representam quem ganha até 2 salários mínimos mensais, concentram $12,3 \%$ do total das declarações; a faixa seguinte, de 2 a 3, concentra 15,3\% das declarações. A faixa de 5 a 7 salários mínimos e a faixa de 7 a 10 salários mínimos concentram, juntas, 25,5\% das declarações, quase o mesmo que a faixa imediatamente anterior ( 3 a 5 salários-mínimos).

Tabela 1 - Resumo das declarações por faixa de rendimentos, ano base 2018 (em milhões de reais)

\begin{tabular}{cccccccc}
\hline & & $(\mathbf{A})$ & $(\mathbf{B})$ & $(\mathbf{C})$ & $(\mathbf{D})$ & $(\mathbf{E})$ & (F) \\
\hline $\begin{array}{c}\text { Faixa de Salário } \\
\text { Mín. Mensal }\end{array}$ & $\begin{array}{c}\text { Qtde } \\
\text { Declarantes }\end{array}$ & $\begin{array}{c}\text { Rendim. } \\
\text { Tribut. }\end{array}$ & $\begin{array}{c}\text { Rendim. } \\
\text { Tribut. Exclus. }\end{array}$ & $\begin{array}{c}\text { Rendim. } \\
\text { Isentos }\end{array}$ & $\begin{array}{c}\text { Rendimentos } \\
\text { Totais }\end{array}$ & $\begin{array}{c}\text { Bens e } \\
\text { Direitos }\end{array}$ & $\begin{array}{c}\text { Dívidas e } \\
\text { Onus }\end{array}$ \\
\hline Até 1/2 & 1.351 .834 & 381 & 80 & 169 & 630 & 225.224 & 35.098 \\
De 1/2 a 1 & 640.769 & 5.792 & 161 & 503 & 6.457 & 62.709 & 5.102 \\
De 1 a 2 & 1.578 .831 & 22.228 & 994 & 3.878 & 27.099 & 174.047 & 14.660 \\
De 2 a 3 & 4.437 .466 & 112.036 & 4.988 & 10.054 & 127.077 & 453.477 & 33.703 \\
De 3 a 5 & 7.945 .451 & 284.758 & 22.705 & 41.037 & 348.500 & 683.227 & 66.297 \\
De 5 a 7 & 4.220 .858 & 218.490 & 19.867 & 41.210 & 279.566 & 583.462 & 132.769 \\
De 7 a 10 & 3.192 .689 & 224.716 & 22.407 & 51.632 & 298.754 & 630.663 & 60.578 \\
\hline
\end{tabular}

(continua) 
Tabela 1 - Resumo das declarações por faixa de rendimentos, ano base 2018 (em milhões de reais) (CONTINUAÇÃO)

\begin{tabular}{cccccccc}
\hline & & $(\mathbf{A})$ & $(\mathbf{B})$ & $(\mathbf{C})$ & $(\mathbf{D})$ & $(\mathbf{E})$ & $(\mathbf{F})$ \\
\hline $\begin{array}{c}\text { Faixa de Salário } \\
\text { Mín. Mensal }\end{array}$ & $\begin{array}{c}\text { Qtde } \\
\text { Declarantes }\end{array}$ & $\begin{array}{c}\text { Rendim. } \\
\text { Tribut. }\end{array}$ & $\begin{array}{c}\text { Rendim. } \\
\text { Tribut. Exclus. }\end{array}$ & $\begin{array}{c}\text { Rendim. } \\
\text { Isentos }\end{array}$ & $\begin{array}{c}\text { Rendimentos } \\
\text { Totais }\end{array}$ & $\begin{array}{c}\text { Bens e } \\
\text { Direitos }\end{array}$ & $\begin{array}{c}\text { Dívidas e } \\
\text { Onus }\end{array}$ \\
\hline De 10 a 15 & 2.429 .334 & 235.735 & 26.202 & 69.871 & 331.809 & 740.099 & 150.848 \\
De 15 a 20 & 1.128 .245 & 145.801 & 18.945 & 53.888 & 218.635 & 577.178 & 48.354 \\
De 20 a 30 & 1.037 .001 & 173.923 & 26.609 & 82.061 & 282.594 & 763.198 & 97.980 \\
De 30 a 40 & 466.460 & 101.953 & 18.372 & 60.149 & 180.473 & 535.535 & 35.660 \\
De 40 a 60 & 352.400 & 89.288 & 22.415 & 78.914 & 190.618 & 617.297 & 40.845 \\
De 60 a 80 & 125.910 & 35.498 & 12.914 & 48.701 & 97.113 & 339.507 & 19.552 \\
De 80 a 160 & 127.080 & 40.268 & 22.407 & 91.056 & 153.731 & 627.616 & 32.454 \\
De 160 a 240 & 29.341 & 11.893 & 10.146 & 41.738 & 63.777 & 290.567 & 17.634 \\
De 240 a 320 & 12.670 & 6.423 & 6.437 & 26.449 & 39.309 & 180.760 & 7.706 \\
Mais de 320 & 25.177 & 27.953 & 60.108 & 206.774 & 294.835 & 1.433 .675 & 55.613 \\
Total & $\mathbf{2 9 . 1 0 1 . 5 1 6}$ & $\mathbf{1 . 7 3 7 . 1 3 6}$ & $\mathbf{2 9 5 . 7 5 6}$ & $\mathbf{9 0 8 . 0 8 4}$ & $\mathbf{2 . 9 4 0 . 9 7 6}$ & $\mathbf{8 . 9 1 8 . 2 4 2}$ & $\mathbf{8 5 4 . 8 5 5}$ \\
\hline
\end{tabular}

Fonte: Elaboração própria com dados da Receita Federal (BRASIL, 2018).

Quem ganha entre 80 e 160 salários-mínimos por mês representa 0,44\% das declarações; de 160 a 240 salários-mínimos por mês, representa $0,10 \%$ do total; entre 240 e 320 salários-mínimos por mês, representa 0,04\% do total. Os 25.177 declarantes da última faixa representam 0,1\% das declarações. Em 2018, quem ganha acima de 320 salários-mínimos, ou seja, mais de R \$305.000,00 mensais, representa 10\% da renda total declarada e uma renda média de $\mathrm{R} \$ 11,7$ milhões.

A coluna (D) representa o total da renda e foi calculada pela soma das colunas (A), (B) e (C), e nos permite observar que os contribuintes que recebem acima de 60 salários mínimos têm, no mínimo, metade de sua renda composta por rendimentos não tributáveis. Para quem ganha acima de 320 salários mínimos, 70\% da renda total não é tributada.

Situação oposta ocorre com a primeira faixa, de quem ganha 1 salário mínimo, na qual $92 \%$ da renda total são rendimentos tributáveis ou com tributação exclusiva. A Tabela 2 mostra o percentual que cada parte do rendimento representa no total para todas as faixas de renda. Essa renda, ao não ser tributada, diminui a arrecadação potencial da Receita Federal e contribui para um gap tributário ainda maior, que é definido como a diferença entre a arrecadação potencial e a arrecadação efetiva.

Nem toda renda isenta é composta de lucros e dividendos. Bolsas de estudos, indenizações e transferências do governo também são isentos e, portanto, não podem ser tributadas. O total dos Rendimentos Isentos e Não Tributáveis somou, em 2018, $\mathrm{R} \$ 957$ bilhões. Deste total, lucros e dividendos somaram R \$327 bilhões, ou seja, 34\%. Se essa parcela fosse tributada, a arrecadação aumentaria consideravelmente. 
Tabela 2 - Composição dos rendimentos totais, ano base 2018

\begin{tabular}{|c|c|c|c|c|}
\hline $\begin{array}{l}\text { Faixa de Salário } \\
\text { Mín. Mensal }\end{array}$ & Rendim. Tribut. & $\begin{array}{l}\text { Rendim. Tribut. } \\
\text { Exclus. }\end{array}$ & Rendim. Isentos & Rendimentos Totais \\
\hline Até $1 / 2$ & $59 \%$ & $14 \%$ & $27 \%$ & $100 \%$ \\
\hline De $1 / 2$ a 1 & $89 \%$ & $3 \%$ & $8 \%$ & $100 \%$ \\
\hline De 1 a 2 & $82 \%$ & $4 \%$ & $14 \%$ & $100 \%$ \\
\hline De 2 a 3 & $88 \%$ & $4 \%$ & $8 \%$ & $100 \%$ \\
\hline De 3 a 5 & $82 \%$ & $7 \%$ & $12 \%$ & $100 \%$ \\
\hline De 5 a 7 & $78 \%$ & $7 \%$ & $15 \%$ & $100 \%$ \\
\hline De 7 a 10 & $75 \%$ & $8 \%$ & $17 \%$ & $100 \%$ \\
\hline De 10 a 15 & $71 \%$ & $8 \%$ & $21 \%$ & $100 \%$ \\
\hline De 15 a 20 & $67 \%$ & $9 \%$ & $25 \%$ & $100 \%$ \\
\hline De 20 a 30 & $62 \%$ & $9 \%$ & $29 \%$ & $100 \%$ \\
\hline De 30 a 40 & $57 \%$ & $10 \%$ & $33 \%$ & $100 \%$ \\
\hline De 40 a 60 & $48 \%$ & $11 \%$ & $41 \%$ & $100 \%$ \\
\hline De 60 a 80 & $37 \%$ & $13 \%$ & $51 \%$ & $100 \%$ \\
\hline De 80 a 160 & $26 \%$ & $14 \%$ & $60 \%$ & $100 \%$ \\
\hline De 160 a 240 & $19 \%$ & $15 \%$ & $66 \%$ & $100 \%$ \\
\hline De 240 a 320 & $16 \%$ & $16 \%$ & $68 \%$ & $100 \%$ \\
\hline Mais de 320 & $9 \%$ & $20 \%$ & $71 \%$ & $100 \%$ \\
\hline
\end{tabular}

Fonte: Elaboração própria com dados da DIRPF (BRASIL, 2018).

Vale ressaltar que os dados apresentados até agora são de renda e não de riqueza. A riqueza, como argumenta Piketty (2014), é sempre mais concentrada, em qualquer país. Medeiros (2015) nos mostra alguns dos principais problemas referentes à estimativa da distribuição da riqueza patrimonial no Brasil a partir dos dados tributários disponíveis, a saber: i) individualização; ii) precificação; e iii) declarações mal efetuadas.

O primeiro trata da falta de individualização do patrimônio de casais, que deveria ser declarado uma única vez, mas frequentemente é declarado de forma duplicada. O segundo diz respeito à defasagem dos valores dos patrimônios, pois esses são declarados com o valor de sua venda ou aquisição e podem sofrer variações ao longo dos anos que não são atualizadas nas declarações. O terceiro considera que pode haver superdeclaração, subdeclararão ou, ainda, a não-declaração de certos bens e direitos, o que torna impossível mensurá-los. Isso se deve ao fato de que um grupo de pessoas pode ter um patrimônio, porém não ter renda suficiente que as obrigue a fazer uma declaração de Imposto de Renda; assim, ocultando esse patrimônio, além de bens e direitos declarados em nomes de pessoas jurídicas. Medeiros (2015) conclui que a riqueza no Brasil é extremamente concentrada, mas ainda não é possível estimar com precisão o grau dessa concentração. 
Os dados das DIRPF permitem analisar o valor total do patrimônio declarado pelos contribuintes, na coluna de Bens e Direitos. A Tabela 3 traz um panorama da distribuição do patrimônio brasileiro de acordo com a declaração do Imposto de Renda, ano base 2018.

Tabela 3 - Patrimônio DIRPF 2018 (em milhões de reais)

\begin{tabular}{|c|c|c|c|c|c|}
\hline $\begin{array}{l}\text { Faixa de Salário } \\
\text { Mín. Mensal }\end{array}$ & $\begin{array}{c}\text { Qtde } \\
\text { Declarantes }\end{array}$ & Bens e Direitos & Dívidas e Ônus & $\begin{array}{l}\text { Patrimônio } \\
\text { Líquido }\end{array}$ & $\begin{array}{l}\text { Patrimônio } \\
\text { Médio }\end{array}$ \\
\hline Até $1 / 2$ & 1.351 .834 & 225.224 & 35.098 & 190.125 & 0,14 \\
\hline De $1 / 2$ a 1 & 640.769 & 62.709 & 5.102 & 57.607 & 0,09 \\
\hline De 1 a 2 & 1.578 .831 & 174.047 & 14.660 & 159.386 & 0,10 \\
\hline De 2 a 3 & 4.437 .466 & 453.477 & 33.703 & 419.774 & 0,09 \\
\hline De 3 a 5 & 7.945 .451 & 683.227 & 66.297 & 616.930 & 0,08 \\
\hline De 5 a 7 & 4.220 .858 & 583.462 & 132.769 & 450.693 & 0,11 \\
\hline De 7 a 10 & 3.192 .689 & 630.663 & 60.578 & 570.085 & 0,18 \\
\hline De 10 a 15 & 2.429 .334 & 740.099 & 150.848 & 589.251 & 0,24 \\
\hline De 15 a 20 & 1.128 .245 & 577.178 & 48.354 & 528.824 & 0,47 \\
\hline De 20 a 30 & 1.037 .001 & 763.198 & 97.980 & 665.218 & 0,64 \\
\hline De 30 a 40 & 466.460 & 535.535 & 35.660 & 499.875 & 1,07 \\
\hline De 40 a 60 & 352.400 & 617.297 & 40.845 & 576.452 & 1,64 \\
\hline De 60 a 80 & 125.910 & 339.507 & 19.552 & 319.955 & 2,54 \\
\hline De 80 a 160 & 127.080 & 627.616 & 32.454 & 595.162 & 4,68 \\
\hline De 160 a 240 & 29.341 & 290.567 & 17.634 & 272.933 & 9,30 \\
\hline De 240 a 320 & 12.670 & 180.760 & 7.706 & 173.055 & 13,66 \\
\hline Mais de 320 & 25.177 & 1.433 .675 & 55.613 & 1.378 .063 & 54,73 \\
\hline Total & 29.101.516 & 8.918 .242 & 854.855 & 8.063 .388 & 0,28 \\
\hline
\end{tabular}

Fonte: Elaboração própria com dados da DIRPF (BRASIL, 2018).

O Patrimônio Líquido, coluna (G) da tabela, é calculado pela subtração da coluna (E) pela coluna (F), ou seja, o patrimônio total descontado de eventuais dívidas. A última coluna, Patrimônio Médio $(\mathrm{H})$, foi calculada como o Patrimônio Líquido $(\mathrm{G})$ dividido pela quantidade de declarantes. A média não é uma boa medida da concentração de riqueza, mas na ausência de uma distribuição do patrimônio é uma boa aproximação.

Pode-se observar que os contribuintes que declaram ganhar acima de 320 salários mínimos mensais, acumulam patrimônio total de quase $\mathrm{R} \$ 1,4$ bilhões, o que equivale a um patrimônio médio de quase $\mathrm{R} \$ 55$ milhões! Esses dados mostram que o patrimônio das últimas faixas é extremamente alto e a real distribuição deve ser ainda mais alarmante. Provavelmente, na última faixa a concentração da riqueza é maior, com muitos contribuintes com menos que a média e poucos com muito mais que a média.

Os dados sobre patrimônio também nos permitem analisar quanto da concentração de riqueza é perpetuada entre as gerações. Com isso, fica fácil perceber que uma 
tributação sobre a riqueza no Brasil, além de ser necessária, tem grande alcance para uma arrecadação sólida. A base de cálculo deve ser todo o patrimônio líquido do contribuinte, com alta faixa de isenção e, eventualmente, alguma dedução, como ocorre em outros países, por exemplo, em que se desconta da base de cálculo o imóvel residencial total ou parcialmente. Dessa forma, o IGF cumpriria perfeitamente sua função.

\section{PANORAMA ATUAL DA TRIBUTAÇÃO BRASILEIRA}

Esta seção apresenta a composição atual da carga tributária brasileira (até o último dado disponível, de 2018), com o objetivo de evidenciar sua regressividade e a falta de uma cobrança efetiva sobre a riqueza no Brasil.

A tributação no Brasil é atualmente regida pelo Código Tributário Nacional, promulgado em 1967, e pela Constituição Federal, promulgada em 1988. Com o fim da Ditadura e a restauração do processo democrático, uma nova Constituição foi elaborada. Mesmo que o objetivo primordial da nova Carta Magna não fosse alterar o sistema tributário, ela trouxe importantes modificações ao modelo de tributação nacional que, já naquela época, era considerado obsoleto.

No que diz respeito às finanças públicas, a nova Constituição estabelece maior autonomia fiscal aos estados e municípios, aumento dos repasses da União e desconcentração dos recursos tributários. Ou seja, visa reduzir a centralização que foi acentuada pelo regime autoritário. $O$ regime democrático também privilegiou a questão social que, durante a Ditadura, perdeu prioridade para a questão econômica. Dessa forma, a nova Constituição aumentou os gastos públicos e promoveu descentralização das receitas. Para combater os desequilíbrios fiscais e perdas de recursos, o governo adotou algumas medidas compensatórias que pioraram a qualidade do sistema tributário.

Houve, assim, a instituição de novos tributos e elevação de alíquotas daqueles que não têm repasse para estados e municípios, tais como a CSLL, cuja arrecadação fica totalmente com a União. Demais contribuições sociais foram instituídas enquanto impostos já estabelecidos, como o Imposto sobre Produtos Industrializados (IPI) e o IR, que têm ampla base de incidência e igual potencial de arrecadação, foram pouco utilizados pelo fato de terem suas receitas compartilhadas. Com o aumento dos gastos sociais e o pagamento de juros, o governo federal precisou aumentar sua receita para evitar déficits nas contas públicas. Evitando a criação de novos impostos, foram instituídas mais taxas e contribuições, com o objetivo principal de equilibrar as contas públicas.

As frequentes alterações no sistema tributário o tornaram ineficiente, causam distorções nos mercados sem resolver a origem do problema: o desequilíbrio entre as competências de arrecadar e os gastos. O sistema tributário brasileiro é considerado 
complexo pela quantidade de tributos e alíquotas existentes e sua carga tributária elevada para o nível de desenvolvimento do país.

A carga tributária bruta (CTB) do Brasil seguiu tendência de crescimento até 2013, mas teve queda em 2014 e 2015 por conta da desaceleração econômica. Ainda assim, apresentou arrecadação em torno de $33 \%$ do PIB no período. Comparativamente a países da América Latina, o Brasil apresenta a maior carga tributária da região, bem acima de média de $22 \%$. Já em relação a países da Organização para a Cooperação e Desenvolvimento Econômico (OCDE), o Brasil se encontra na média, apesar de ter CTB mais elevada que países de semelhantes níveis de desenvolvimento, tais como México (19\% do PIB) e Turquia (26\%); e também de países mais desenvolvidos, tais como: EUA (25\%), Suíça (30\%) e Canadá (31\%). No entanto, aparece abaixo de outros países europeus como França (42\%) e Alemanha (37\%) (OCDE, 2019).

Além do tamanho da carga tributária, é importante analisar sua composição. A CTB brasileira é extremamente concentrada, pois a maior parte (70\%) dos tributos é de competência da União. A CTB também pode ser considerada regressiva, pois é majoritariamente composta por tributos indiretos, que recaem sobre o consumo e oneram mais as classes sociais mais baixas, e menos por impostos diretos, incidentes sobre o capital, a propriedade e seus rendimentos. O Gráfico 1 evidencia o exposto acima, com a maior parte da arrecadação sendo de tributos indiretos.

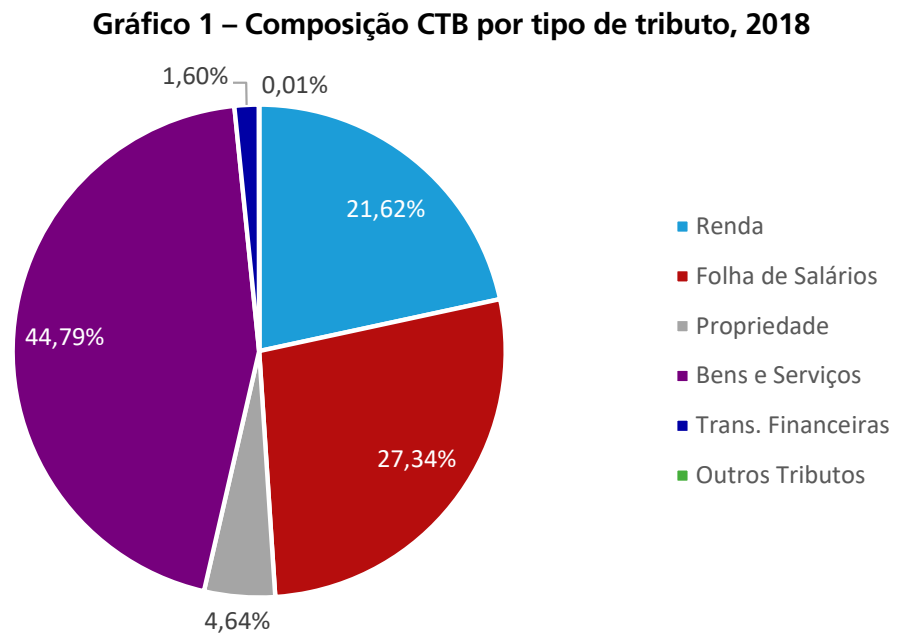

Fonte: Elaboração própria a partir de dados da Receita Federal (BRASIL, 2019).

Observa-se que $45 \%$ da carga tributária total é composta por tributos sobre o consumo, $27 \%$ sobre folha de salário e apenas $22 \%$ de tributos sobre a renda. Chama atenção também o fato de que menos de $5 \%$ da carga tributária bruta total brasileira é composta 
por tributos sobre a propriedade, que no Brasil são: o Imposto Territorial Rural (ITR), o Imposto sobre Propriedade Territorial Urbana (IPTU) e o Imposto sobre Propriedade Veicular Automotiva (IPVA). Nesse valor estão incluídos também os tributos sobre transferências: o Imposto sobre Transmissão de Bens Imóveis Inter-vivos (ITBI) e o Imposto sobre Transmissão de Bens Causa-mortis ou Doação (ITCMD).

Os tributos sobre propriedade, ainda que progressivos, têm baixa arrecadação, representando 4,6\% da CTB e pouco menos de 1,5\% do PIB em 2018. Apesar da baixa representatividade, esses tributos têm crescido em arrecadação e percentual do PIB ao longo da última década, conforme mostra o Gráfico 2.

\section{Gráfico 2 - Tributos sobre propriedade, em arrecadação e \% do PIB, 2002-2018}

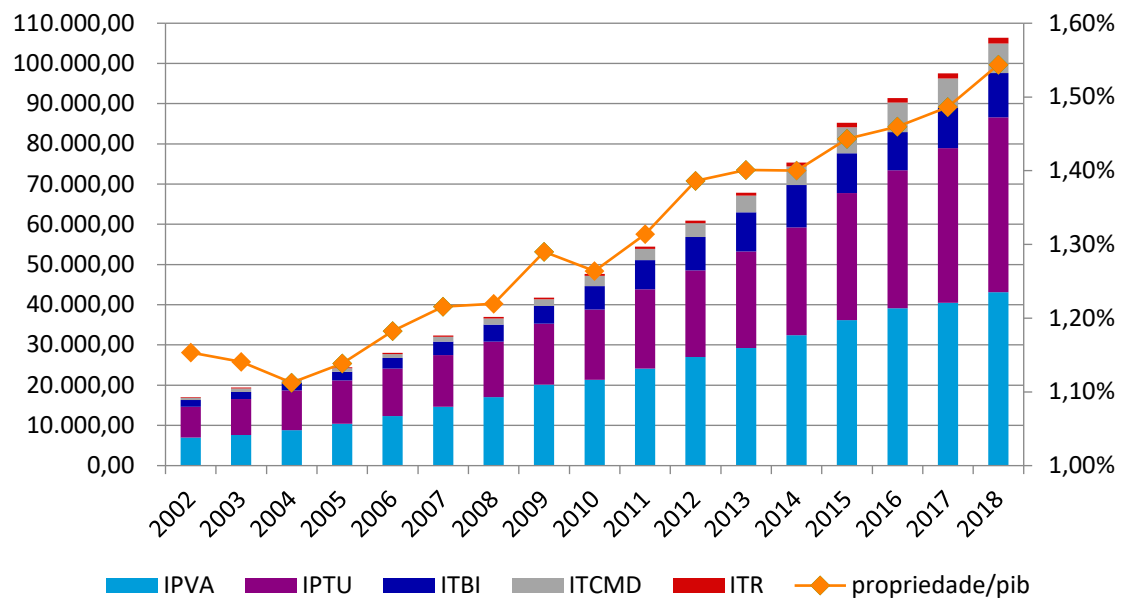

Fonte: Elaboração própria a partir de dados da Receita Federal (BRASIL, 2019).

O IPVA e o IPTU são os maiores arrecadadores dos tributos sobre patrimônio e, em 2018, representaram, respectivamente, $42 \%$ e 35\% do total arrecadado nesse tipo de tributação. Há uma grande discussão se o IPVA deveria incidir sobre iates, embarcações, jatos e helicópteros. Por ser um tributo sobre veículos automotivos, faria sentido incidir também sobre estes veículos, como ocorre em outros países. Porém, o IPVA é decorrente da Taxa Rodoviária Única, e o STF já julgou improcedente sua cobrança sobre veículos que não sejam terrestres (Informativo 462 do STF).

No entanto, a legislação tributária sobre propriedades imóveis é passível de mudanças. O ITR tem potencial para ter uma arrecadação mais sólida, apesar de ser de difícil fiscalização. O IPTU pode ser progressivo ou conter diferentes alíquotas para contribuintes com mais de um imóvel. É possível, ainda, efetuar mudanças pontuais que melhorem a arrecadação, como a incidência do IPVA (ou outro tributo de propriedade semelhante) sobre jatos e embarcações. 
A segunda maior fonte de arrecadação da carga tributária brasileira é o Imposto de Renda que tem cinco faixas de cobranças progressivas, como mostra a Tabela 4. Uma das principais críticas ao IRPF brasileiro é que sua alíquota máxima é baixa em comparação com outros países (AFONSO; SOARES; CASTRO, 2013), além de não ter tido ajuste em relação à inflação nos últimos cinco anos.

Tabela 4 - Tabela com faixas do Imposto de Renda Pessoa Física, Brasil, 2020

\begin{tabular}{|c|c|}
\hline Alíquota de IRPF & Tabela atual \\
\hline Isento & Até R\$1.903,98 \\
\hline $7,5 \%$ & De $\mathrm{R} \$ 1.903,99$ até $\mathrm{R} \$ 2.826,66$ \\
\hline $15,0 \%$ & De $\mathrm{R} \$ 2.826,67$ até $\mathrm{R} \$ 3.451,05$ \\
\hline $22,5 \%$ & De R $\$ 3.751,06$ até $\mathrm{R} \$ 4.664,68$ \\
\hline $27,5 \%$ & Acima de $\mathrm{R} \$ 4.664,68$ \\
\hline
\end{tabular}

Fonte: Elaboração própria.

Apesar de a maior alíquota marginal ser de 27,5\% para rendas mensais acima de $\mathrm{R} \$ 4.664,68$, a alíquota efetiva paga pelo contribuinte pode ser bem menor. Uma simples simulação realizada com uma renda mensal de $\mathrm{R} \$ 5.000,00$ permite concluir que a alíquota efetiva é de 7,3\%, já descontando a previdência, como mostra a Tabela 5 .

Tabela 5 - Simulação de alíquota efetiva para renda mensal de R\$ 5.000,00

\begin{tabular}{lccc}
\hline \multicolumn{2}{c}{ Faixa da Base de Cálculo } & Alíquota & Valor do Imposto \\
\hline $1^{\text {a }}$ Faixa & $1.903,98$ & Isento & 0,00 \\
$2^{\text {a }}$ Faixa & 922,67 & $7,5 \%$ & 69,20 \\
$3^{\text {a }}$ Faixa & 924,40 & $15,0 \%$ & 138,66 \\
$4^{\text {a }}$ Faixa & 698,5 & $22,5 \%$ & 157,26 \\
$5^{\text {a Faixa }}$ & 0,00 & $27,5 \%$ & 0,00 \\
Total Efetivo & $\mathbf{4 . 4 5 0 , 0 0}$ & $\mathbf{7 , 3 0 \%}$ & $\mathbf{3 6 5 , 1 2}$ \\
\hline
\end{tabular}

Fonte: Elaboração própria com base em dados da Receita Federal (BRASIL, 2018).

Outra possível crítica trata-se das faixas de renda que são "sufocadas" pela baixa progressividade e acabam onerando mais a classe média. O Brasil já teve IRPF com alíquotas maiores incidentes sobre mais faixas de renda, o que o fazia ser mais progressivo. A maior alíquota foi de 65\% da renda na década de 1960 e, até a década de 1980, o IRPF tinha mais de 10 faixas em sua legislação. É curioso observar que foi justamente em 1988, quando houve a promulgação da Constituição Cidadã, que tanto o número de alíquotas quanto a alíquota máxima foram reduzidos, diminuindo a progressividade do imposto. 
Com isso, observa-se que a carga tributária brasileira pode ser reorganizada, de forma a ter sua maior parte composta por tributos diretos e progressivos, que incidam sobre a renda e o patrimônio do contribuinte. De todos os tributos desse gênero, o único não regulamentado, até o momento, é o Imposto sobre Grandes Fortunas.

\subsection{IMPOSTO SOBRE GRANDES FORTUNAS}

No Brasil, o Imposto sobre Grandes Fortunas (IGF) está previsto pela Constituição Federal (CF) de 1988 no artigo 153, VII, de competência da União, porém, pendente de lei complementar e, até o momento, não foi instituído. A dependência da legislação faz o IGF ter uma eficácia limitada, sendo necessária a definição de "grandes fortunas", a base de cálculo e a estipulação de alíquotas para que entre em vigor.

O Ato das Disposições Constitucionais Transitórias, ${ }^{2}$ em seu art. 80, inciso III, estipula: "Art. 80. Compõem o Fundo de Combate e Erradicação da Pobreza: [...] III - o produto da arrecadação do imposto de que trata o Art. 153, inciso VII, da Constituição" (BRASIL, 1988). Trata-se, portanto, de um imposto de grande potencial para a realização de justiça social no Brasil, na medida em que sua intenção é diminuir a desigualdade de riqueza e contribuir para a melhoria da distribuição de renda no país.

Tema de fundamental importância, ela ainda é pouco discutida no Congresso, a despeito das propostas já apresentadas. O jornal O Globo (O QUE PENSA..., 2015) fez um levantamento com os 513 deputados eleitos em 2014 sobre diversos temas, entre eles, o IGF. Segundo o jornal, 307 deputados (60\%) apoiam a regulamentação do imposto, 101 são contra e 105 não responderam. O IGF é o único dos treze impostos previstos na Constituição que ainda não entrou em vigor. Há diferentes propostas de regulamentação do IGF em pauta no Congresso, algumas em trâmite desde 1989, mas até hoje nenhuma foi aprovada. A ideia é que o IGF seja um imposto direto e progressivo, com alíquotas baixas, elevada faixa de isenção e aplicado somente a altos valores de riqueza para pessoas físicas e jurídicas.

A experiência internacional nos mostra que é possível tributar a riqueza de diversas formas, através do próprio imposto sobre fortunas ou do imposto sobre propriedade e renda. Também mostra que é comum tributar a riqueza com o objetivo de distribuir renda e limitar o acúmulo de capital. Assim, uma tributação sobre a riqueza seria essencial para reduzir a desigualdade e a concentração de renda no Brasil.

\footnotetext{
2 ADCT: Anexo à Constituição, prevê adaptações na transição do ordenamento jurídico. Estabelece as normas enquanto a legislação prevista na Constituição não é instituída.
} 


\subsection{PROPOSTAS DE IMPLEMENTAÇÃO DO IGF}

Já foram apresentadas, até dezembro de 2019, mais de 30 propostas $^{3}$ para implementação do IGF no Brasil, por diferentes partidos, tanto na Câmara quanto no Senado. Os projetos de lei propõem diferentes bases de cálculo, alíquotas e justificativas. Foram analisadas somente as propostas que tratam especificamente da implementação do IGF e desconsideradas as diversas propostas de reforma tributária já protocoladas, bem como eventuais propostas de emendas constitucionais para extinção do tributo.

Todos os projetos de lei apresentados devem conter, ao final, uma justificativa de sua implementação. Sem exceção, todos citam a grande desigualdade de renda do Brasil, o princípio da solidariedade, previsto no art. $3^{\circ}$ da CF, que preza pela justiça social e erradicação da pobreza, e o princípio da capacidade contributiva, segundo o qual quem tem mais deve contribuir, proporcionalmente, mais.

As propostas a partir de 2015 tratam também da questão do ajuste fiscal promovido pelo governo e como esse tributo poderia ajudar a aumentar a arrecadação, suprindo eventuais lacunas causadas pela perda de arrecadação em outros setores. É importante notar que muitas das propostas trazem deduções relevantes, como o imóvel residencial.

A maioria das propostas sugere alíquotas progressivas seguindo, assim, o princípio da capacidade contributiva e o verdadeiro objetivo do imposto, que é tributar os mais ricos e diminuir a concentração da renda. Os projetos de lei definem a base de cálculo sobre quais bens incidirá o tributo e como será feita a valoração dos mesmos. Preveem, ainda, regras para declaração de bens com mais de um titular, como cônjuges, e permitem a dedução do valor já pago em demais tributos de propriedade, para evitar a dupla tributação. A próxima seção apresenta simulações de arrecadação com base nas propostas apresentadas e a partir dos dados disponíveis.

\section{METODOLOGIA DA SIMULAÇÃO}

Não está disponível no Brasil, ainda, a distribuição da riqueza e do patrimônio. O melhor dado público que existe para esse tipo de estimativa é a Declaração do Imposto de Renda Pessoa Física (DIRPF), na qual há uma coluna intitulada "Bens e Direitos" que contabiliza todo o patrimônio dos contribuintes, porém sem distinção do tipo de bens. A Receita Federal divulga os bens agregados, não discriminados e, portanto, é difícil fazer uma estimativa sobre o patrimônio real de cada contribuinte.

\footnotetext{
3 A Tabela A1 do apêndice resume as propostas.
} 
Além disso, há muitos bens que não são declarados, simplesmente porque não há necessidade. Jóias e obras de arte, por exemplo, fazem parte da base de cálculo do IGF em diversos países. Apesar de a lei exigir que se declarem todos os bens, como não há cruzamento de dados entre as diversas bases, muitas vezes alguns bens não são declarados. Por exemplo, como o IPVA é de competência estadual e o IR de competência federal, suas bases de dados não cruzam; então, se o contribuinte não quiser declarar que tem um automóvel em seu nome, ele pode não o fazer. Por outro lado, se o contribuinte declara que tem certos bens, mas sua renda não é compatível com o poder de aquisição desses bens, a Receita Federal o inclui na "malha fina” gerando problemas futuros para suas declarações. Por exemplo, num caso extremo, se o contribuinte declara uma renda de $\mathrm{R} \$ 5.000,00$ mensais e tem um iate em seu nome, o cruzamento de dados considera incompatível e o contribuinte acaba na malha fina.

Foram feitos dois tipos de simulações: progressivas ou com alíquotas únicas com limites de isenções de R $\$ 2$ milhões, R 5 milhões e R\$ 10 milhões, que resultaram em dez casos, resumidos a seguir. Com uma declaração estática, ou seja, sem a distribuição dos bens, é impossível aplicar alíquotas progressivas dentro de uma mesma faixa de renda, pois não se sabe exatamente qual o patrimônio real de cada contribuinte.

As primeiras simulações (casos i a v) supõem que o valor de isenção seria de $\mathrm{R}$ \$ 2 milhões de reais, considerando que R \$ 1 milhão seja o valor de um imóvel residencial em uma grande capital do Brasil atualmente e, portanto, o contribuinte precisaria de mais R \$ 1 milhão para que seu patrimônio seja considerado como fortuna. Novamente, como a Receita Federal apenas divulga os dados agregados, ou seja, apenas informa o valor total de Bens e Direitos, sem distinção do valor individual, é impossível deduzir o valor real do que é imóvel residencial na declaração. Por isso, optou-se por estabelecer o valor de imóvel em R\$ 1 milhão.

Com base nos projetos mais recentes, que têm valores de isenção mais altos, pode-se fazer uma simulação em que a faixa isenta seja de $\mathrm{R} \$ 5$ milhões (casos vi a ix), com alíquotas únicas ou progressivas de $0,5 \%, 1 \%$ e $1,5 \%$. Nesses casos, apenas contribuintes que ganham acima de 160 salários mínimos seriam tributados. Por fim, o último caso (x) tem limite de isenção de $\mathrm{R} \$ 10$ milhões e duas alíquotas progressivas de $1 \%$ e $3 \%$.

O cálculo da arrecadação, então, foi feito da seguinte maneira: sobre o valor do patrimônio líquido médio (coluna $\mathrm{H}$ ) de todos os declarantes, aplica-se as alíquotas (progressivas ou única, de $0,5 \%, 1 \%$ ou $1,5 \%$ ) e, ao final, multiplica-se pelo número de contribuintes de cada faixa e soma-se o total. A alíquota não pode ser aplicada sobre o valor total dos Bens e Direitos (coluna E), pois, neste caso, não se estaria deduzindo o valor da isenção. A coluna Base de Cálculo (I) foi calculada pela média do patrimônio líquido descontado da faixa de isenção. Sobre essa base, aplica-se a alíquota proposta, chegando ao valor da coluna Arrecadação Individual (J). O Valor Total da Arrecadação, 
coluna (K), é calculado, então, multiplicando o valor da arrecadação individual (J) pelo número de declarantes de cada faixa de renda. Os valores monetários encontram-se todos em milhões de reais. A Tabela 6 faz uma simulação extra para exemplificar.

Tabela 6 - Simulação extra

\begin{tabular}{|c|c|c|c|c|c|c|}
\hline Isenção R\$ 2 mi & $(\mathrm{H})$ & & (I) & (J) & & $(\mathrm{K})$ \\
\hline $\begin{array}{c}\text { Faixa de Salário } \\
\text { Min. Mensal }\end{array}$ & $\begin{array}{l}\text { Patrimônio } \\
\text { Médio }\end{array}$ & Alíquotas \% & $\begin{array}{l}\text { Base de } \\
\text { Cálculo }\end{array}$ & $\begin{array}{c}\text { Arrecadação } \\
\text { Individual }\end{array}$ & Declarantes & Total \\
\hline De 40 a 60 & $\mathrm{R} \$ 1,64$ & isento & $\mathrm{R} \$ 0,00$ & $\mathrm{R} \$ 0,00000$ & 352.400 & $\mathrm{R} \$ 0,00$ \\
\hline De 60 a 80 & $\mathrm{R} \$ 2,54$ & 0,5 & $\mathrm{R} \$ 0,54$ & $\mathrm{R} \$ 0,00271$ & 125.910 & $\mathrm{R} \$ 340,68$ \\
\hline De 80 a 160 & $\mathrm{R} \$ 4,68$ & 1 & $\mathrm{R} \$ 2,68$ & $\mathrm{R} \$ 0,02683$ & 127.080 & $\mathrm{R} \$ 3.410,02$ \\
\hline De 160 a 240 & $\mathrm{R} \$ 9,30$ & 2 & $\mathrm{R} \$ 7,30$ & $\mathrm{R} \$ 0,14604$ & 29.341 & $\mathrm{R} \$ 4.285,02$ \\
\hline De 240 a 320 & $\mathrm{R} \$ 13,66$ & 3 & $\mathrm{R} \$ 11,66$ & $\mathrm{R} \$ 0,34976$ & 12.670 & $\mathrm{R} \$ 4.431,44$ \\
\hline \multirow[t]{3}{*}{ Mais de 320} & $\mathrm{R} \$ 54,73$ & 5 & $\mathrm{R} \$ 52,73$ & $\mathrm{R} \$ 2,63675$ & 25.177 & $\mathrm{R} \$ 66.385,44$ \\
\hline & & & & & \multicolumn{2}{|c|}{ em milhões de R\$ } \\
\hline & & & & & total & $\mathrm{R} \$ 78.852,59$ \\
\hline
\end{tabular}

Fonte: Elaboração própria.

Serão apresentados em detalhes os resultados dos casos (i), (v), (vi), (ix) e (x), cada um com sua especificidade. Ao final uma comparação é apresentada na Tabela 12 que resume todos os casos, suas respectivas arrecadações e percentuais na carga tributária de 2018.

Os resultados apresentados têm limitações. Devido à ausência de uma base de dados mais completa da distribuição do patrimônio brasileiro, a simulação é feita com base na média de Bens e Direitos declarados no Imposto de Renda. Alguns valores acabam sendo subestimados, já que não se aplica a alíquota sobre o valor real de cada contribuinte. Por outro lado, ela pode superestimar alguns casos, já que, devido à falta da discriminação de bens, não é possível descontar eventuais bens dedutíveis nem valores pagos em demais tributos de propriedade, se fosse o caso. Apesar de a base de cálculo ser, eventualmente, a mesma (o apartamento no caso do IPTU, carros no caso do IPVA), o fato gerador é diferente e, portanto, não configura bitributação.

\section{RESULTADOS DAS SIMULAÇÕES DE ARRECADAÇÃO}

No caso (i), a simulação foi feita com isenção de $\mathrm{R} \$ 2$ milhões e alíquotas progressivas de $0,5 \%$ a $3 \%$ incidentes sobre o patrimônio líquido médio. Como a média do patrimônio líquido de quem ganha entre 60 e 80 salários mínimos mensais é de $\mathrm{R} \$ 2,54$ milhões, a base de cálculo para essa faixa de renda é de R $\$ 540$ mil. Para quem ganha acima de 320 salários mínimos mensais, o patrimônio líquido médio é de R \$ 54,73 milhões e, 
com o valor isento, a base de cálculo é de R\$ 52,73 milhões. Neste caso, a arrecadação do IGF seria de quase R $\$ 50$ bilhões e representaria, sozinha, 2,3\% da carga tributária total de 2018. A Tabela 7 mostra o exposto.

Tabela 7 - Simulação i: isenção de R\$ 2 milhões e alíquotas progressivas

\begin{tabular}{ccccccc}
\hline $\begin{array}{c}\text { Faixa de Salário } \\
\text { Mín. Mensal }\end{array}$ & $\begin{array}{c}\text { Patrimônio } \\
\text { Médio }\end{array}$ & Alíquotas \% & $\begin{array}{c}\text { Base de } \\
\text { Cálculo }\end{array}$ & $\begin{array}{c}\text { Arrecadação } \\
\text { Individual }\end{array}$ & Declarantes & Total \\
\hline De 40 a 60 & $\mathrm{R} \$ 1,64$ & isento & $\mathrm{R} \$ 0,00$ & $\mathrm{R} \$ 0,00000$ & 352.400 & $\mathrm{R} \$ 0,00$ \\
De 60 a 80 & $\mathrm{R} \$ 2,54$ & 0,5 & $\mathrm{R} \$ 0,54$ & $\mathrm{R} \$ 0,00271$ & 125.910 & $\mathrm{R} \$ 340,68$ \\
De 80 a 160 & $\mathrm{R} \$ 4,68$ & 1 & $\mathrm{R} \$ 2,68$ & $\mathrm{R} \$ 0,02683$ & 127.080 & $\mathrm{R} \$ 3.410,02$ \\
De 160 a 240 & $\mathrm{R} \$ 9,30$ & 1,5 & $\mathrm{R} \$ 7,30$ & $\mathrm{R} \$ 0,10953$ & 29.341 & $\mathrm{R} \$ 3.213,76$ \\
De 240 a 320 & $\mathrm{R} \$ 13,66$ & 2 & $\mathrm{R} \$ 11,66$ & $\mathrm{R} \$ 0,23317$ & 12.670 & $\mathrm{R} \$ 2.954,29$ \\
Mais de 320 & $\mathrm{R} \$ 54,73$ & 3 & $\mathrm{R} \$ 52,73$ & $\mathrm{R} \$ 1,58205$ & 25.177 & $\mathrm{R} \$ 39.831,26$ \\
& & & & & total & $\mathrm{R} \$ 49.750,02$ \\
\hline
\end{tabular}

Fonte: Elaboração própria com dados da DIRPF (BRASIL, 2018).

No caso (v), a simulação foi feita com isenção de $\mathrm{R} \$ 2$ milhões e alíquotas únicas de 1,5\% incidentes sobre o patrimônio líquido médio. Neste caso, a arrecadação do IGF seria de pouco mais de $\mathrm{R} \$ 31$ bilhões e representaria, sozinha, 1,5\% da carga tributária total de 2018. Mesmo com a alíquota única sendo elevada (1,5\%), a arrecadação com alíquotas progressivas (caso i) foi maior, o que demonstra que a tributação progressiva, além de mais justa, ainda é mais eficiente. A Tabela 8 mostra o exposto.

Tabela 8 - Simulação v: isenção de R\$ 2 milhões e alíquota única

\begin{tabular}{ccccccc}
\hline $\begin{array}{c}\text { Faixa de Salário } \\
\text { Mín. Mensal }\end{array}$ & $\begin{array}{c}\text { Patrimônio } \\
\text { Médio }\end{array}$ & Alíquotas \% & $\begin{array}{c}\text { Base de } \\
\text { Cálculo }\end{array}$ & $\begin{array}{c}\text { Arrecadação } \\
\text { Individual }\end{array}$ & Declarantes & Total \\
\hline De 40 a 60 & $\mathrm{R} \$ 1,64$ & isento & $\mathrm{R} \$ 0,00$ & $\mathrm{R} \$ 0,00000$ & 352.400 & $\mathrm{R} \$ 0,00$ \\
De 60 a 80 & $\mathrm{R} \$ 2,54$ & 1,5 & $\mathrm{R} \$ 0,54$ & $\mathrm{R} \$ 0,00812$ & 125.910 & $\mathrm{R} \$ 1.022,03$ \\
De 80 a 160 & $\mathrm{R} \$ 4,68$ & 1,5 & $\mathrm{R} \$ 2,68$ & $\mathrm{R} \$ 0,04025$ & 127.080 & $\mathrm{R} \$ 5.115,03$ \\
De 160 a 240 & $\mathrm{R} \$ 9,30$ & 1,5 & $\mathrm{R} \$ 7,30$ & $\mathrm{R} \$ 0,10953$ & 29.341 & $\mathrm{R} \$ 3.213,76$ \\
De 240 a 320 & $\mathrm{R} \$ 13,66$ & 1,5 & $\mathrm{R} \$ 11,66$ & $\mathrm{R} \$ 0,17488$ & 12.670 & $\mathrm{R} \$ 2.215,72$ \\
Mais de 320 & $\mathrm{R} \$ 54,73$ & 1,5 & $\mathrm{R} \$ 52,73$ & $\mathrm{R} \$ 0,79102$ & 25.177 & $\mathrm{R} \$ 19.915,63$ \\
& & & & & total & $\mathrm{R} \$ 31.482,18$ \\
\hline
\end{tabular}

Fonte: Elaboração própria com dados da DIRPF (BRASIL, 2018).

No caso (vi), a simulação foi feita com isenção de R 5 milhões e alíquotas progressivas de $0,5 \%, 1 \%$ e 1,5\% incidentes sobre o patrimônio líquido médio. Neste caso, a arrecadação do IGF seria em torno de $\mathrm{R} \$ 20,5$ bilhões, o que representaria quase $1 \%$ da carga tributária total de 2018. 
Tabela 9 - Simulação vi: isenção de R\$ 5 milhões e alíquotas progressivas

\begin{tabular}{ccccccc}
\hline $\begin{array}{c}\text { Faixa de Salário } \\
\text { Mín. Mensal }\end{array}$ & $\begin{array}{c}\text { Patrimônio } \\
\text { Médio }\end{array}$ & Alíquotas $\%$ & $\begin{array}{c}\text { Base de } \\
\text { Cálculo }\end{array}$ & $\begin{array}{c}\text { Arrecadação } \\
\text { Individual }\end{array}$ & Declarantes & Total \\
\hline De 40 a 60 & $\mathrm{R} \$ 1,64$ & isento & $\mathrm{R} \$ 0,00$ & $\mathrm{R} \$ 0,00000$ & 352.400 & $\mathrm{R} \$ 0,00$ \\
De 60 a 80 & $\mathrm{R} \$ 2,54$ & isento & $\mathrm{R} \$ 0,00$ & $\mathrm{R} \$ 0,00000$ & 125.910 & $\mathrm{R} \$ 0,00$ \\
De 80 a 160 & $\mathrm{R} \$ 4,68$ & isento & $\mathrm{R} \$ 0,00$ & $\mathrm{R} \$ 0,00000$ & 127.080 & $\mathrm{R} \$ 0,00$ \\
De 160 a 240 & $\mathrm{R} \$ 9,30$ & 0,5 & $\mathrm{R} \$ 4,30$ & $\mathrm{R} \$ 0,02151$ & 29.341 & $\mathrm{R} \$ 631,14$ \\
De 240 a 320 & $\mathrm{R} \$ 13,66$ & 1 & $\mathrm{R} \$ 8,66$ & $\mathrm{R} \$ 0,08659$ & 12.670 & $\mathrm{R} \$ 1.097,05$ \\
Mais de 320 & $\mathrm{R} \$ 54,73$ & 1,5 & $\mathrm{R} \$ 49,73$ & $\mathrm{R} \$ 0,74602$ & 25.177 & $\mathrm{R} \$ 18.782,67$ \\
& & & & & total & $\mathrm{R} \$ 20.510,85$ \\
\hline
\end{tabular}

Fonte: Elaboração própria com dados da DIRPF (BRASIL, 2018).

É possível observar que com o mesmo limite de isenção alto de $\mathrm{R} \$ 5$ milhões, as alíquotas progressivas arrecadam quase o mesmo que as alíquotas únicas, ainda que esta esteja fixada em 1,5\%. Isso fica ainda mais evidente ao comparar os casos (vi) e (ix). Na simulação (ix), a faixa de isenção continua em R 5 milhões, mas aplica-se alíquotas únicas de 1,5\%. Neste caso, a arrecadação seria pouco abaixo de R $\$ 20$ bilhões. As Tabelas 9 e 10 confirmam tal ideia.

Tabela 10 - Simulação ix: isenção de R\$ 5 milhões e alíquota única

\begin{tabular}{ccccccc}
\hline $\begin{array}{c}\text { Faixa de Salário } \\
\text { Mín. Mensal }\end{array}$ & $\begin{array}{c}\text { Patrimônio } \\
\text { Médio }\end{array}$ & Alíquotas \% & $\begin{array}{c}\text { Base de } \\
\text { Cálculo }\end{array}$ & $\begin{array}{c}\text { Arrecadação } \\
\text { Individual }\end{array}$ & Declarantes & Total \\
\hline De 40 a 60 & $\mathrm{R} \$ 1,49$ & isento & $\mathrm{R} \$ 0,00$ & $\mathrm{R} \$ 0,00000$ & 352.400 & $\mathrm{R} \$ 0,00$ \\
De 60 a 80 & $\mathrm{R} \$ 2,35$ & isento & $\mathrm{R} \$ 0,00$ & $\mathrm{R} \$ 0,00000$ & 125.910 & $\mathrm{R} \$ 0,00$ \\
De 80 a 160 & $\mathrm{R} \$ 4,25$ & isento & $\mathrm{R} \$ 0,00$ & $\mathrm{R} \$ 0,00000$ & 127.080 & $\mathrm{R} \$ 0,00$ \\
De 160 a 240 & $\mathrm{R} \$ 8,22$ & 1,5 & $\mathrm{R} \$ 3,22$ & $\mathrm{R} \$ 0,04834$ & 29.341 & $\mathrm{R} \$ 1.418,30$ \\
De 240 a 320 & $\mathrm{R} \$ 12,51$ & 1,5 & $\mathrm{R} \$ 7,51$ & $\mathrm{R} \$ 0,11268$ & 12.670 & $\mathrm{R} \$ 1.427,67$ \\
Mais de 320 & $\mathrm{R} \$ 50,20$ & 1,5 & $\mathrm{R} \$ 45,20$ & $\mathrm{R} \$ 0,67799$ & 25.177 & $\mathrm{R} \$ 17.069,72$ \\
& & & & & total & $\mathrm{R} \$ 19.915,68$ \\
\hline
\end{tabular}

Fonte: Elaboração própria com dados da DIRPF (BRASIL, 2018).

Por fim, o caso (x) traz uma isenção de R\$ 10 milhões, ou seja, incidiria apenas sobre o patrimônio de pessoas que ganham acima de 240 salários mínimos por mês e, portanto, configuram o cume da pirâmide de distribuição de renda do Brasil. Neste caso, com alíquotas progressivas de $1 \%$ e 3\%, a arrecadação do IGF seria de quase R $\$ 31$ bilhões de reais e representaria 1,4\% da carga tributária de 2018.

Observa-se que, mesmo com maiores faixas de isenções, as alíquotas progressivas são mais eficientes que a alíquota única, tanto em termos de arrecadação quanto de justiça tributária. Isso está de acordo com o princípio da capacidade contributiva e corrobora a ideia de que quem tem mais deve contribuir proporcionalmente mais. 
Tabela 11 - Simulação x: isenção de R\$ 10 milhões e alíquota única

\begin{tabular}{ccccccc}
\hline $\begin{array}{c}\text { Faixa de Salário } \\
\text { Mín. Mensal }\end{array}$ & $\begin{array}{c}\text { Patrimônio } \\
\text { Médio }\end{array}$ & Alíquotas \% & $\begin{array}{c}\text { Base de } \\
\text { Cálculo }\end{array}$ & $\begin{array}{c}\text { Arrecadação } \\
\text { Individual }\end{array}$ & Declarantes & Total \\
\hline De 40 a 60 & $\mathrm{R} \$ 1,49$ & isento & $\mathrm{R} \$ 0,00$ & $\mathrm{R} \$ 0,00000$ & 352.400 & $\mathrm{R} \$ 0,00$ \\
De 60 a 80 & $\mathrm{R} \$ 2,35$ & isento & $\mathrm{R} \$ 0,00$ & $\mathrm{R} \$ 0,00000$ & 125.910 & $\mathrm{R} \$ 0,00$ \\
De 80 a 160 & $\mathrm{R} \$ 4,25$ & isento & $\mathrm{R} \$ 0,00$ & $\mathrm{R} \$ 0,00000$ & 127.080 & $\mathrm{R} \$ 0,00$ \\
De 160 a 240 & $\mathrm{R} \$ 8,22$ & isento & $\mathrm{R} \$ 0,00$ & $\mathrm{R} \$ 0,00000$ & 29.341 & $\mathrm{R} \$ 0,00$ \\
De 240 a 320 & $\mathrm{R} \$ 12,51$ & 1 & $\mathrm{R} \$ 2,51$ & $\mathrm{R} \$ 0,02512$ & 12.670 & $\mathrm{R} \$ 318,28$ \\
Mais de 320 & $\mathrm{R} \$ 50,20$ & 3 & $\mathrm{R} \$ 40,20$ & $\mathrm{R} \$ 1,20598$ & 25.177 & $\mathrm{R} \$ 30.362,88$ \\
& & & & & total & $\mathrm{R} \$ 30.681,16$ \\
\hline
\end{tabular}

Fonte: Elaboração própria com dados da DIRPF (BRASIL, 2018).

A Tabela 12 traz um resumo de todas as simulações feitas. Vale notar que o caso (i) tem a maior arrecadação, mas também a maior base de cálculo e alíquotas mais progressivas. $\mathrm{O}$ caso (ii) apresenta arrecadação semelhante à do caso (i), no entanto, as alíquotas são menos progressivas. Observa-se que as demais simulações com isenções de R 2 milhões, ainda que incidam sobre mais de 300 mil contribuintes, não se refletem em maiores contribuições, pois foram feitas com alíquotas únicas. A partir do caso (vi), a isenção é de $\mathrm{R} \$ 5$ milhões e a incidência é sobre pouco menos de 70 mil contribuintes. O caso (vi), com alíquotas progressivas, apresenta arrecadação maior que os casos (vii), (viii) e (ix), todos com alíquotas únicas. $\mathrm{O}$ caso (x) apresenta uma arrecadação intermediária, apesar do alto limite de isenção. Isso se deve ao fato de que suas alíquotas progressivas, ainda que incidam sobre um menor número de contribuintes (37.847), incidem sobre a maior parte da base de cálculo, já que os maiores patrimônios estão nas últimas duas faixas (em especial a última).

A partir da análise feita, é fácil observar que o Brasil tem uma base de arrecadação sólida para o IGF. No entanto, conforme supracitado, essa simulação está baseada em dados não detalhados. A falta de distribuição do patrimônio não permite que se apliquem alíquotas progressivas pelo valor da base de cálculo, o que subestima o potencial arrecadatório. Além disso, sem a distinção dos bens, a alíquota está aplicada sobre o patrimônio líquido total, o que não viabiliza uma tributação específica para diferentes tipos de riqueza. Com o processo de financeirização, boa parte da riqueza atual se dá na forma de ativos financeiros, não mais de ativos físicos (como fazendas e imóveis), o que permite maior mobilidade da riqueza para países com menor tributação onde proporcionará maior rendimento. No entanto, também é possível rastrear os recursos que migram de um país a outro e firmar acordos internacionais para que haja cooperação de tributação nesses casos. 


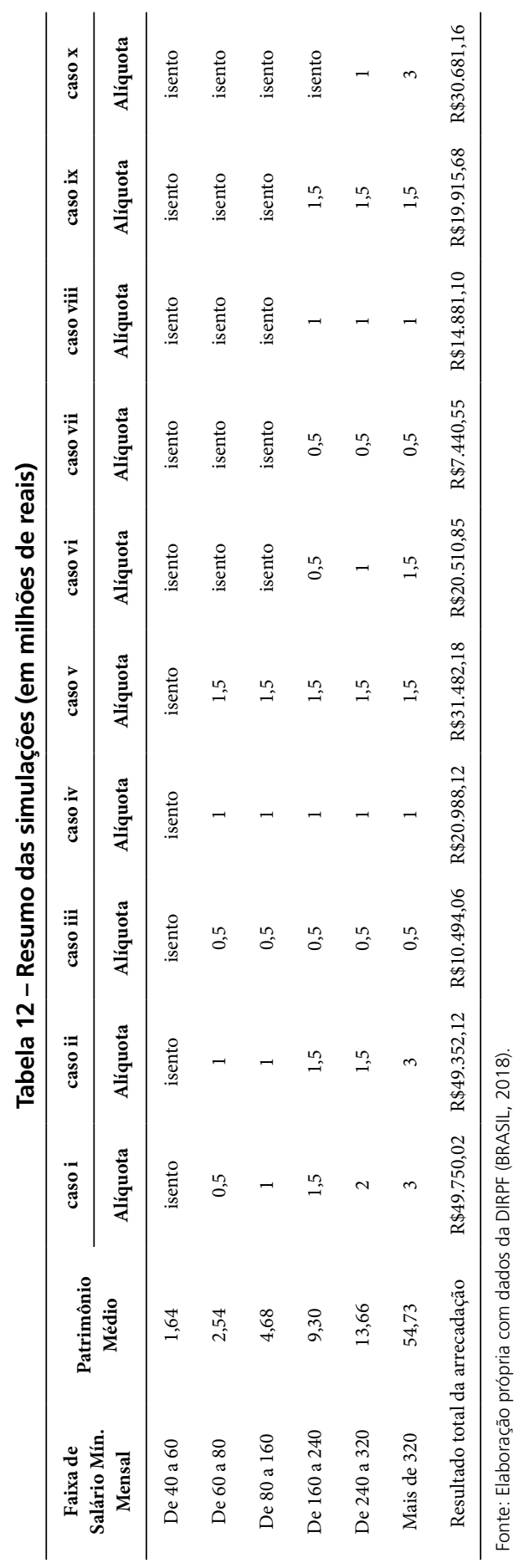




\section{CONCLUSÃO}

A ampliação dos gastos sociais nos últimos anos contribuiu para a redução da pobreza, mas a discrepância de rendimentos ainda é muito elevada e a renda muito concentrada no topo da distribuição. Com isso, conclui-se que não só a tributação sobre a renda, mas também sobre o patrimônio, poderia ser mais expressiva a fim de reduzir a desigualdade no Brasil.

O presente trabalho procurou mostrar como a tributação da riqueza pode contribuir para reduzir a desigualdade através de um imposto específico aos mais ricos, que pode não apenas limitar a acumulação como também redistribuir os recursos. $O$ texto analisou em linhas gerais como funciona a carga tributária no Brasil, com atenção aos tributos de propriedade, e evidenciou a concentração de renda e riqueza a partir dos dados das Declarações do Imposto de Renda Pessoa Física de 2018 divulgados pela Receita Federal. Também caracterizou o IGF e simulou propostas para sua implementação.

Com o objetivo de responder à pergunta se o IGF é viável e tem sólida arrecadação, diferentes simulações foram feitas, calculando o valor de arrecadação desse tributo e seu percentual em relação ao PIB. A partir disso, conclui-se que o Brasil tem uma base de arrecadação sólida para o IGF e sua implementação é viável, dado que a concentração de renda e riqueza é evidente e não arrefeceu nos últimos anos.

Caberia então, a um tributo específico sobre a riqueza trabalhar para tentar amenizar essa concentração. A maior parte da renda dos mais ricos vem, justamente, de rendimentos não tributáveis, o que os permite acumular ainda mais renda e patrimônio, acentuando ainda mais a desigualdade. Uma tributação mais efetiva sobre o patrimônio faria a carga tributária brasileira ser mais progressiva e, assim, mais justa. A implementação do IGF contribuiria para diminuir a regressividade, aumentar a arrecadação e, eventualmente, desonerar alguns tributos indiretos que causam injustiça tributária.

O Imposto sobre Grandes Fortunas está previsto no ordenamento jurídico, com diferentes propostas de implementação já apresentadas ao Congresso. Sua implementação é viável, com extensa base de cálculo e arrecadação sólida.

Entretanto, nem todos são a favor do IGF. O principal argumento contra o tributo é de que ele teria baixa arrecadação e difícil fiscalização, argumento que pode ser facilmente contraposto. Como mostra este trabalho, o resultado obtido da simulação da arrecadação é significativo, com média de arrecadação de 1,2\% do PIB, chegando a 2,3\% nos casos (i) e (ii), que, sozinha, representa mais do que a arrecadação de todos os tributos de propriedade em 2018, que somaram 1,5\% do PIB. Este valor representa, por exemplo, todo o orçamento do Bolsa Família para 2018 e um quarto do orçamento da educação e pode, ainda, contribuir para o ajuste fiscal proposto pelo governo, contrapondo o argumento da não implementação do tributo por baixa arrecadação. Além disso, com a atualização e cruzamento das bases de dados, sua fiscalização seria facilitada. 
Há, ainda, o argumento de que outros tributos diretos, sobre renda, herança e patrimônio, cumprem bem o papel de desconcentrar renda. Porém, a evidência empírica mostra que o tributo sobre riqueza não substitui os demais tributos, mas sim, os complementa. Além disso, como a carga tributária brasileira é extremamente regressiva, os tributos diretos têm baixa representatividade e um imposto direto e progressivo caberia bem no sistema tributário.

Apesar da ausência de uma base de dados mais detalhada, a simulação realizada mostra que há espaço para a tributação das riquezas no Brasil, seja pela ausência de uma tributação mais efetiva sobre a riqueza e o patrimônio, seja por sua arrecadação significativa, ou simplesmente como forma de desestimular a concentração de renda. Mais que isso, a implementação do IGF poderia ser um primeiro passo para a reformulação da nossa carga tributária.

Há poucos trabalhos que tratam sobre o IGF em si, a maioria no âmbito do Direito, no entanto, autores como Khair (2005) e Carvalho Jr. $(2008,2011)$ desenvolvem pesquisas econômicas defendendo o tema há bastante tempo (ver NUNES, 2019; MARIUZZO, 2014). Algumas pesquisas acadêmicas estão em andamento, principalmente após a implementação do Auxílio Emergencial por conta da pandemia da Covid-19 e da crise fiscal, e podem futuramente ajudar a dar visibilidade e maior compreensão ao IGF.

Este texto descreve a arrecadação patrimonial no Brasil e simula uma eventual arrecadação do IGF no país, contribuindo de forma extremamente relevante para a literatura do tema. No entanto, não esgota o assunto. Estudos futuros sobre diferentes formas de tributação ou até mesmo sobre a viabilidade de implementação do IGF seriam interessantes para ampliar o debate. Ademais, um comparativo internacional com outros países que têm ou tiveram o IGF em seu ordenamento jurídico poderia elucidar melhor o tributo e sua função fiscal e social.

Estudos como os de Hoffmann (2005), Peña et al. (2015) e Castro e Modesto (2010) mostram que apenas os programas de transferência de renda, como o Bolsa Família, não promovem melhorias substanciais no perfil distributivo do país. Embora seja um programa muito importante, que proporciona renda às pessoas mais pobres e, ao fazê-lo, também beneficia a atividade econômica por aumentar seu consumo, não basta para reduzir toda a desigualdade e restaurar a dignidade dessas famílias.

Apenas transferências de renda não são suficientes, é necessário também a provisão dos serviços públicos de qualidade para que haja igualdade de oportunidades. A desigualdade de renda cria desigualdade de oportunidades até mesmo na educação. A pobreza não é apenas sobre a falta de renda, é também sobre habitação, serviços públicos básicos, atenção especial a idosos, crianças e deficientes; são fatores que diminuem a disparidade entre ricos e pobres, criando uma sociedade mais homogênea. Os mercados não possuem um mecanismo que interrompa o processo de acumulação, 
motivo pelo qual o Estado deve promover políticas públicas para reduzí-lo, começando com uma tributação mais justa e progressiva e políticas efetivas de bem-estar social.

Como se trata de um dos países mais desiguais do mundo, uma ampla política redistributiva é necessária. Entretanto, pouco foi feito em relação à reforma tributária. Os tributos progressivos são pouco utilizados como instrumento de justiça fiscal, ou seja, além de a renda e a riqueza já serem extremamente concentradas, a redistribuição não cumpre completamente seus objetivos. Os impostos sobre propriedade e riqueza devem ser mais bem utilizados para limitar a concentração no topo da distribuição. Um sistema tributário mais progressivo pode e deve ser formulado com o propósito de reduzir a desigualdade e o comportamento pró-cíclico da arrecadação, principalmente em épocas de crise e queda na atividade econômica.

O Brasil está passando por uma crise econômica e as propostas do governo incluem apenas cortes nas despesas e reformas no sistema de aposentadoria. Aumentar a tributação de uma maneira justa e eficiente seria uma solução alternativa, já implementada por alguns países europeus para enfrentar a crise e o ajuste fiscal. Seguindo este caminho, o Brasil caminharia para futuramente estar apenas entre os 20 mais ricos, e não entre os 20 mais desiguais.

\section{REFERÊNCIAS}

AFONSO, J. R.; SOARES, J. M.; CASTRO, K. P. Avaliação da estrutura e do desempenho do sistema tributário brasileiro: Livro branco da tributação brasileira. [S. l.]: Banco Interamericano de Desenvolvimento, jan. 2013.

BRASIL. Constituição Federal (1988). Constituição da República Federativa do Brasil. Diário Oficial da União: seção 1, Brasília, DF, ano 126, n. 191-A, p. 1, 5 out. 1988.

BRASIL. Secretaria da Receita Federal. Carga Tributária no Brasil 2018: Análise por Tributos e Bases de Incidência. Brasília, DF: Secretaria da Receita Federal, 2019. Disponível em: www.receita.fazenda.gov.br.

BRASIL. Secretaria da Receita Federal. Grandes Números IRPF - Ano-Calendário 2018, Exercício 2019. Brasília, DF: Secretaria da Receita Federal, 2020. Disponível em: www.receita.fazenda.gov.br.

CARVALHO JR., P. H. B. As discussões sobre a regulamentação do Imposto sobre Grandes Fortunas: a situação no Brasil e a experiência internacional. Rio de Janeiro: IPEA, 2011. (Nota Técnica).

CARVALHO JR., P. H. Imposto sobre grandes fortunas. Desafios do Desenvolvimento, v. 5, n. 43, 17 maio 2008.

CASTRO, J. A.; MODESTO, L. (Orgs.). Bolsa família 2003-2010: avanços e desafios. Brasília, DF: IPEA, 2010. $2 \mathrm{v}$.

CASTRO, F. Á. Imposto de renda pessoa física: comparações internacionais, medidas de progressividade e redistribuição. 2014. Dissertação (Mestrado em Economia do Setor Público) Universidade de Brasília, Brasília, DF, 2014. 
HOFFMANN, R. As transferências não são a causa principal da redução da desigualdade. Econômica, v. 7, n. 2, p. 335-341, 2005.

IPEADATA. Estatísticas Sociais. Coeficiente de Gini. [Online] IPEADATA, 2020. Disponível em: www.ipeadata.gov.br.

KHAIR, A. Imposto sobre Grandes Fortunas (IGF). Rio de Janeiro: Instituto de Economia da UFRJ, 2005. Mimeo.

MARIUZZO, P. Imposto sobre grandes fortunas para reduzir a desigualdade. Ciência e Cultura, v. 66, n. 4, p. 60-62, 2014. Disponível em: https://doi.org/10.21800/S0009-67252014000400018.

MEDEIROS, M. Distribuição da riqueza no Brasil: Limitações a uma estimativa precisa a partir dos dados tabulados do IRPF disponíveis. 15 ago. 2015. Disponível em: http://ssrn.com/ abstract $=2641192$.

MEDEIROS, M.; SOUZA, P. H. G. F.; CASTRO, F. A. O topo da distribuição de renda no Brasil: primeiras estimativas com dados tributários e comparação com pesquisas domiciliares, 2006-2012. Dados, v. 58, n. 1, p. 7-36, 2015.

MORGAN. M. Extreme and persistent inequality: New evidence for Brazil combining national accounts, surveys and fiscal data, 2001-2015. Working Paper, World Wealth and Income Database, n. 2017/12, ago. 2017.

NASCIMENTO, N. A inexistente tributação da riqueza no Brasil e o imposto sobre grandes fortunas. 2016. Dissertação (Mestrado) - Universidade Federal Fluminense, Rio de Janeiro, 2016.

NUNES, C. B. B. Imposto sobre grandes fortunas: um instrumento para a redução da concentração de riqueza no Brasil. 2019. Trabalho de Conclusão de Curso (Bacharelado em Direito) Universidade Federal de Pernambuco, Recife, 2019. Disponível em: https://repositorio.ufpe. br/handle/123456789/37371.

O QUE PENSA a nova Câmara: G1 mostra a opinião dos deputados federais sobre 12 temas polêmicos. G1, Brasília, DF, 31 jan. 2015. Disponível em: http://especiais.g1.globo.com/ politica/2015/o-que-pensa-a-nova-camara/.

ONU - ORGANIZAÇÃO DAS NAÇÕES UNIDAS. The Millennium Development Goals Report 2015. Nova York: ONU, 2015. Disponível em: http://mdgs.un.org/unsd/mdg/Resources/ Static/Products/Progress2015/English2015.pdf.

OCDE - ORGANIZAÇÃO PARA A COOPERAÇÃO E DESENVOLVIMENTO ECONÔMICO. Revenue Statistics - OECD countries: Comparative tables. [On-line] OECD Library, 2019. Doi: http://doi.org/10.1787/data-00262-en.

PEÑA, C. R.; PINHEIRO, D. S.; ALBUQUERQUE, P. H. M.; FERNANDES, L. M. A eficácia das transferências de renda: as tendências da desigualdade antes e depois do Programa Bolsa Família. Revista de Administração Pública, v. 49, n. 4, p. 889-914, 2015. DOI: https://doi.org/ 10.1590/0034-7612135532.

PIKETTY, T. Capital in the Twenty-First Century. Rio de Janeiro: Intrínseca, 2014. 


\section{APÊNDICE}

Tabela A1 - Resumo das propostas analisadas para a simulação

\begin{tabular}{|c|c|c|c|c|c|}
\hline Tipo & Ano & Casa & Autor/partido & Limite de isenção & Alíquotas \\
\hline PL 2097 & 1991 & Câmara & Wilson Campos - PMDB/PE & - & \\
\hline PL 950 & 2011 & Câmara & Dr. Aluizio - PV/RJ & - & \\
\hline PLP 108 & 1989 & Câmara & Juarez Marques Batista - PSDB/MS & 3.000.000 BTN & $1 \% ; 2 \% ; 3 \% ; 4 \%$ \\
\hline PLP 202 & 1989 & Câmara & Fernando Henrique Cardoso - PSDB/SP & $\mathrm{NCz} \$ 2.000 .000,00$ & $\begin{array}{c}0,3 \% ; 0,5 \% \\
0,7 \% ; 1 \%\end{array}$ \\
\hline PLP 208 & 1989 & Câmara & Antonio Mariz - PMDB/PB & 5.000 isenção do IRPF & $0,5 \% ; 1 \% ; 1,5 \%$ \\
\hline PLP 218 & 1990 & Câmara & Poder Executivo & 1.000.000 BTN & $\begin{array}{l}0,1 \% ; 0,2 \% \\
0,4 \% ; 0,7 \%\end{array}$ \\
\hline PLP 268 & 1990 & Câmara & Ivo Cersosimo - PMDB/MS & $50 \%$ ganho de capital & $30 \%$ \\
\hline PLP 70 & 1991 & Câmara & Mavieal Cavalcanti - PRN/PE & - & \\
\hline PLP 77 & 1991 & Câmara & Wilson Campos - PMDB/PE & - & \\
\hline PLP 193 & 1994 & Câmara & Ernesto Gradella - PSTU/SP & R\$ 1 milhão & \\
\hline PLP 277 & 2008 & Câmara & Luciana Genro - PSOL/RS e outros & R\$ 2 milhões & $\begin{array}{c}1 \% ; 2 \% ; 3 \% \\
4 \% ; 5 \%\end{array}$ \\
\hline PLP 26 & 2011 & Câmara & Amaury Teixeira - PT/BA & R\$ 5 milhões & $\begin{array}{c}1 \% ; 2 \% ; 3 \% \\
4 \% ; 5 \%\end{array}$ \\
\hline PLP 48 & 2011 & Câmara & Dr. Aluizio - PV/RJ & $\mathrm{R} \$ 5,5$ milhões & $\begin{array}{c}0,55 \%, 0,75 \% \\
1 \%, 1,3 \% \\
1,65 \%, 1,8 \%\end{array}$ \\
\hline PLP 62 & 2011 & Câmara & Claudio Puty - PT/PA & R\$ 3 milhões & $\begin{array}{c}0,5 \% ; 1 \% \\
1,5 \% ; 2 \%\end{array}$ \\
\hline PLP 130 & 2012 & Câmara & Paulo Teixeira - PT/SP e outros & 8.000 isenção do IRPF & $0,5 \% ; 0,75 \% ; 1 \%$ \\
\hline PLP 2 & 2015 & Câmara & Sarney Filho - PV/MA & R\$ 5 milhões & $\begin{array}{c}0,5 \% ; 0,75 \% \\
1,0 \% ; 1,5 \%\end{array}$ \\
\hline PLP 6 & 2015 & Câmara & Hissa Abrahão - PPS/AM & 6 mil salários mínimos & $0,1 \% ; 0,3 \% ; 0,5 \%$ \\
\hline PLP 11 & 2015 & Câmara & Valmir Assunção - PT/BA & R\$ 5 milhões & $\begin{array}{c}1 \% ; 2 \% ; 3 \% \\
4 \% ; 5 \%\end{array}$ \\
\hline PLS 50 & 2008 & Senado & Serys - PT/MT & 3.000.000 BTN & $\begin{array}{l}0,1 \% ; 0,2 \% \\
0,4 \% ; 0,7 \%\end{array}$ \\
\hline PLS 100 & 2008 & Senado & José Nery - PSOL/PA & R\$ 2 milhões & $\begin{array}{c}1 \% ; 2 \% ; 3 \% \\
4 \% ; 5 \%\end{array}$ \\
\hline PLS 128 & 2008 & Senado & Paulo Paim - PT/RS & R\$ 10 milhões & $1 \%$ \\
\hline PLS 315 & 2015 & Senado & Paulo Paim - PT/RS & $\mathrm{R} \$ 50$ milhões & $1 \%$ \\
\hline PLS 534 & 2011 & Senado & Antonio Carlos Valadares - PSB/SE & $\mathrm{R} \$ 2,5$ milhões & $\begin{array}{c}0,5 \% ; 1 \% ; \\
1,5 \% ; 2 \% ; 2,5 \%\end{array}$ \\
\hline
\end{tabular}

Fonte: Elaboração própria. 